\title{
NIF Ignition Campaign Target Performance and Requirements: Status May 2012
}

S. W. Haan, J. Atherton, D. S. Clark, B. A. Hammel, D. A. Callahan, C. J. Cerjan, E. L. Dewald, S. Dixit, M. J. Edwards, S. Glenzer, S. P. hatchett, D. Hicks, O. S. Jones, O. L. Landen, J. D. Lindl, M. M. Marinak, B. J. MacGowan, A. J. MacKinnon, N. B. Meezan, J. L. Milovich, D. H. Munro, H. F. Robey, J. D. Salmonson, B. K. Spears, L. J. Suter, R. P. Town, S. V. Weber, J. L. Kline, D. C. Wilson

\section{September 21, 2012}

20th Target Fabrication Meeting

Santa Fe, NM, United States

May 20, 2012 through May 24, 2012 
This document was prepared as an account of work sponsored by an agency of the United States government. Neither the United States government nor Lawrence Livermore National Security, LLC, nor any of their employees makes any warranty, expressed or implied, or assumes any legal liability or responsibility for the accuracy, completeness, or usefulness of any information, apparatus, product, or process disclosed, or represents that its use would not infringe privately owned rights. Reference herein to any specific commercial product, process, or service by trade name, trademark, manufacturer, or otherwise does not necessarily constitute or imply its endorsement, recommendation, or favoring by the United States government or Lawrence Livermore National Security, LLC. The views and opinions of authors expressed herein do not necessarily state or reflect those of the United States government or Lawrence Livermore National Security, LLC, and shall not be used for advertising or product endorsement purposes. 
NIF Ignition Campaign Target Performance and Requirements: Status May, 2012

S.W. Haan, J. Atherton, D.S. Clark, B.A. Hammel, D.A. Callahan, C.J. Cerjan, E.L. Dewald, S. Dixit, M.J. Edwards, S. Glenzer, S.P. Hatchett, D. Hicks, O.S. Jones, O.L. Landen, J.D. Lindl, M.M. Marinak, B.J. MacGowan, A.J. MacKinnon, N.B. Meezan, J.L. Milovich, D.H. Munro, H.F. Robey, J.D. Salmonson, B.K. Spears, L.J. Suter, R.P. Town, and S.V. Weber

Lawrence Livermore National Laboratory

J.L. Kline, D.C. Wilson

Los Alamos National Laboratory

Contact:

Steven Haan

L-477, Lawrence Livermore National Laboratory

7000 East Avenue

Livermore, CA 94550

e-mail haan1@Ilnl.gov

Telephone 925-422-4715, Fax 925-422-9690

Following are 15 pages of manuscript, 2 page of figure captions, 9 figures, all black and white or gray-scale 


\title{
NIF ignition campaign target performance and requirements: Status May 2012
}

S.W. Haan, J. Atherton, D.S. Clark, B.A. Hammel, D.A. Callahan, C.J. Cerjan, E.L.

Dewald, S. Dixit, M.J. Edwards, S. Glenzer, S.P. Hatchett, D. Hicks, O.S. Jones, O.L.

Landen, J.D. Lindl, M.M. Marinak, B.J. MacGowan, A.J. MacKinnon, N.B. Meezan, J.L.

Milovich, D.H. Munro, H.F. Robey, J.D. Salmonson, B.K. Spears, L.J. Suter, R.P. Town, and S.V. Weber

Lawrence Livermore National Laboratory

J.L. Kline, D.C. Wilson

Los Alamos National Laboratory

\begin{abstract}
Abstact:
The National Ignition Campaign (NIC) on the National Ignition Facility plans to use an indirectly driven spherical implosion to assemble and ignite a mass of DT fuel. The NIC is currently in the process of conducting a variety of experiments using surrogate targets, meant to define various aspects of the future ignition experiment. Four platforms have been developed: "Reemit" targets measure the symmetry of the early part of the pulse; "Keyhole" targets measure strength and time of shocks; "Symcap" targets measure integrated performance and implosion symmetry; and "ConA" targets measure implosion velocity and ablator performance. Also, cryogenic layered capsules similar to the ignition design, containing a DT or hydrodynamically equivalent tritium-rich fuel layer, are being fielded. These integrate the laser and target adjustments made during the tuning experiments and test the integrated performance with data on RhoR, T, yield, and other diagnostics. In an activity ongoing with these experiments, the point design for ignition is updated and modified as appropriate. This presentation will summarize the target designs that are being used for the campaign, the results of the experimental campaign to date, and how the campaign has affected requirements for the eventual ignition experiment.
\end{abstract}

Prepared by LLNL under Contract DE-AC52-07NA27344. 


\section{INTRODUCTION}

Targets being planned to produce thermonuclear ignition on the National Ignition

Facility $^{1}$ (NIF) will be fabricated to meet requirements based on detailed simulations and implosion analysis. The underlying science is described in Ref. 2, and previous descriptions of the requirements have been published in Refs. 3, 4 and 5. The requirements are formally controlled by the National Ignition Campaign (NIC) program and have been through a series of updates as our understanding of the best possible target has evolved. Generally, the targets are designed and the requirements are set using the two and three-dimensional codes LASNEX ${ }^{6}$ and Hydra. ${ }^{7}$ Details of the roll-up of the specifications and performance were described in Ref. 8, and details of the campaign leading up to ignition in Refs. 5, 9, 10 and 11. At the time of this writing, the last formally adopted requirements were Rev5, as described in Ref. 5; the target design has been updated in various ways as described below, but a new set of requirements has not been adopted.

The ignition target is shown in Figs. 1 and 2. The spherical fusion capsule, Fig. 1, is defined by a shell made of a $\mathrm{C}_{0.423} \mathrm{H}_{0.572} \mathrm{O}_{0.005}$ plastic called Glow Discharge Polymer (GDP). The GDP shell is composed of five layers doped with various amounts of Si. Two different Si configurations have been shot; one configuration designated "1 $\mathrm{x}$ " has layers of $0-1-2-1-0$ at $\%$, and the other designated " $2 x$ " has layers of $0-2-4-2-0$ at $\%$. Dimensions of the interior layers are as described previously. ${ }^{5,8}$ The interior of this shell is filled with DT fusion fuel, brought in through the indicated $10 \mu \mathrm{m}$-diameter borosilicate glass tube and a $5 \mu \mathrm{m}$ hole. The target is cooled to the DT triple point of about $20 \mathrm{~K}$, and the DT is 
formed into a $69 \mu \mathrm{m}$-thick layer of solid DT by temperature control through the betalayering process. ${ }^{12}$ The central sphere is DT gas, in solid-vapor equilibrium with the solid DT. This spherical "capsule" is centered in a cylindrical can called a "hohlraum," Fig. 2, made of $\mathrm{Au}$ or of an $\mathrm{Au} / \mathrm{U} / \mathrm{Au}$ sandwich. Details of the hohlraum geometry are as previously described. ${ }^{5,8}$ The capsule is supported between two formvar films, each about $100 \mathrm{~nm}$ thick, called the "tent." The ends of the cylinder have holes through which the laser beams enter, as shown in Fig. 2. The interior of the hohlraum is filled with He gas, density $0.96 \mathrm{mg} / \mathrm{cc}$, which holds back the Au from filling the hohlraum during the shot. The laser entrance holes are covered with $0.5 \mu \mathrm{m}$-thick plastic windows, to contain the He fill. As shown in Fig. 2, the cylindrical Au hohlraum is supported by Si paddles through which heat is removed from the (pre-shot) cryogenic assembly; temperature control is provided by heater wires around the hohlraum.

During the shot, the interior of the hohlraum is heated by the laser to a peak temperature of $300 \mathrm{eV}$, or $3.5 \times 10^{6} \mathrm{~K}$. Ablation of the GDP drives the DT to very high velocity $(\sim 350 \mathrm{~km} / \mathrm{s})$, and stagnation of the assembly on center creates the high temperature and density needed for fusion. Rising rapidly to the high pressure required for this acceleration would shock the fuel, rendering it insufficiently compressible; instead, a carefully timed series of preliminary pulses compresses the GDP and the DT with a series of four relatively weak shocks, before the main pressure pulse accelerates the shells. A typical laser pulse is shown in Fig. 3. A measure of the compressibility of the fuel is the adiabat, which in our usage is synonymous to the isentrope, of the cold fuel that ultimately must be compressed. The compressed DT gas, along with the inner 10$15 \%$ of the solid DT, forms a central hot spot in which the DT is hot enough for fusion to 
produce $10^{14}$ or more neutrons. The hot-spot is surrounded by a shell of highly compressed main fuel which confines it while it burns. If the hot-spot reaches temperature above about $3 \mathrm{keV}$ (average), with column density of $0.3 \mathrm{~g} / \mathrm{cm}^{2}$ or more, confined by at least $\sim 1.0 \mathrm{~g} / \mathrm{cm}^{2}$ of dense main fuel, then it is expected that the energy deposition from the burn heats the hot-spot further and ignition follows. ${ }^{2}$

The beams enter the hohlraum in 4 cones, through each LEH. These are typically grouped into "inner cones" at $22.5^{\circ}$ and $30^{\circ}$, and "outer cones" at $44.5^{\circ}$ and $50^{\circ}$. The inner and outer cones have slightly different pulse shapes and wavelengths, to control symmetry. A particularly important parameter is the wavelength difference between the various cones, since power is transferred between the beams as they enter the hohlraum, via scattering off sound waves in the plasma. The power transfer can be varied by changing the wavelengths. ${ }^{13}$

Many features of this experiment were defined by simulations that have been validated and normalized by experiments on smaller laser facilities. But a number of details need to be refined by preliminary experiments that are designed to measure some specific features of the fusion experiment; these experiments comprise the National Ignition Campaign, described in more detail below. At the time of this conference, this campaign is well underway, with many successes in hand and some challenges ahead. We have successfully fielded all of the experimental platforms planned for NIC, and used the results to adjust the target design and laser pulse. (See Refs. 9 and 10 for descriptions of the campaign plans, and Refs. 13-15 for updates on the results of the experiments.) The point design target has been adjusted slightly from when it was last published; the current designs are shown in Fig. 1. Changes have been made in the dimensions of the 
hohlraum, and the use of Si rather than Ge as the capsule dopant. For the future, as described in more detail below, the emphasis will be on exploring a range of targets with various dopant configurations and shell thicknesses.

This article has five sections following: (ii) Description and status of the various subcampaigns within NIC; (iii) Status of DT implosions; (iv) Capsule support tent; (v) Oxygen in GDP ablators; and (vi) Future directions.

\section{IGNITION TUNING CAMPAIGN}

Five experimental platforms were successfully developed and have been used to refine details of the ignition experiment. They will be described here in chronological order through the pulse:

\section{II.A. Re-emit targets}

In a Re-emit target the central spherical capsule assembly is replaced with a bismuth sphere, which is viewed through a film-covered hole in the side of the hohlraum. The re-emitted radiation from the Bi sphere is imaged and used to ascertain the symmetry during the first $2 \mathrm{~ns}$ of the pulse. (At later times the radiation from other parts of the target, and interaction between the $\mathrm{Bi}$ and the hohlraum gas, render the measurement less useful.) These have ben used successfully several times to set the cone-to-cone power ratio during the early part of the pulse.

A variant on the Re-emit is called the Patchless Re-emit, in which there is no hole in the side of the hohlraum (hence no patch over the hole), and the Bi ball is viewed through a laser entrance hole. This is used to ascertain azimuthal symmetry of the 
radiation environment during the first 2 ns. The azimuthal asymmetry can be controlled by changing the power of the $23.5^{\circ}$ and $30^{\circ}$ cones, which have different azimuthal configurations. It also depends on the wavelength difference between the $23.5^{\circ}$ and $30^{\circ}$ cones, relative to the outer cones.

\section{II.B. Keyhole targets}

In a Keyhole target the DT fuel and gas are replaced with liquid deuterium, and the interior of the capsule is made visible through a re-entrant cone as shown in Fig. 4. The shock traveling through the ablator, and then the DD, is measured by a diagnostic called VISAR (Velocity Interferometer System for Any Reflector) ${ }^{16}$. The VISAR light reflects off the first shock front that it encounters, and measures its speed towards the instrument. Initially this is the first shock launched by the "picket" at 1-2 ns; later the $2^{\text {nd }}$ shock, launched by the rise at $12 \mathrm{~ns}$, overtakes the first, and is measured by the VISAR; later the $3^{\text {rd }}$ and $4^{\text {th }}$ respectively are observed. The measurement thus returns the overtake times, and subsequent shock velocities, for each of the 4 shocks. (Soon after the $4^{\text {th }}$ shock appears, overall heating of the system blanks VISAR and the shock is no longer visible.) Integrating the velocity provides the radius vs. time of the leading propagating shock. Shock strengths and times can then be adjusted to provide optimal compression of the fuel. ${ }^{17}$ The keyhole campaign ${ }^{14}$ has been very successful, demonstrating excellent reproducibility and allowing for very accurate tuning of the shock coalescence in liquid DD. An updated "dual axis" design has been fielded in which part of the field of view of the VISAR is occupied by a mirror at $45^{\circ}$, allowing measurement of the shock propagation both at the waist—opposite the usual keyhole axis, the usual view—and at the pole, as reflected in the mirror. A remaining issue is the possibility of differences 
between the full sphere of liquid DD and the $69 \mu \mathrm{m}$-thick layer of solid DT; this is planned to be addressed in the future with keyhole targets that have an actual-thickness DT layer.

\section{II.C. Symcap targets}

A "symcap" is the same as the target shown in Figs. 1 and 2, except that there is no solid fuel layer and the gas is changed to (typically) $7 \mathrm{mg} / \mathrm{cc}$ of $70: 30{ }^{3} \mathrm{He}: \mathrm{D}$. The thickness of the innermost (undoped) layer of GDP is increased by 13 microns to provide the same "payload" mass as the DT layer. These targets have lower convergence than the DT layered targets, and are simpler to field. They are used to characterize the hohlraum symmetry and the laser-plasma interactions (LPI). Many symcaps have been successfully fielded, allowing demonstration of adequate LPI overall, adequate symmetry, and control

of the symmetry via changes in the wavelengths of the cones. ${ }^{13}$ As a result of the symcap experiments, the geometry of the hohlraum was modified slightly from the original configuration $^{8}$ to a wider shorter design. ${ }^{13}$ Implosion times of symcaps (as well as the other high-velocity targets) are consistently later than expected from simulations, indicating velocity $5-10 \%$ lower than predicted.

\section{II.D. Backlit capsule "ConA" targets}

In a "ConA" target, a slot is cut in the waist of the hohlraum; the slot is $100 \mu \mathrm{m}$ wide, $2400 \mu \mathrm{m}$ long, and held open with high-density carbon. ${ }^{18}$ An area-backlighter external to the hohlraum is illuminated by two of the 48 quads, and pinhole imaging of the backlit imploding shell allows measurement of its trajectory. Analysis of the image also provides the remaining unablated mass vs time, and the density and thickness of the imploding shell. The imploding ConA capsule is typically a symcap, although a shot was 
also done that had a layer of cryogenic fuel and correspondingly thinner GDP. The ConA targets have confirmed the reduced velocity indicated by the late bang-time of the symcaps and layered targets. The ConA results also suggest that the remaining unablated mass is often less than expected, and that the density of the remaining ablator is often lower than expected. However, it remains arguable whether these discrepancies are systematically outside the uncertainties in comparison to the simulations.

\section{II.E. THD targets}

In a THD target the DT fuel is replaced with a different isotope ratio, typically 75$\mathrm{x}: 25-\mathrm{x}: 2 \mathrm{x}$ for $\mathrm{T}: \mathrm{H}: \mathrm{D}$, with $\mathrm{x}$ ranging so that the $\mathrm{D}$ fraction varies from $2-6 \mathrm{at} \%$. The DT neutron yield, which is typically much larger than the TT neutron yield, is proportional to the amount of D. This allows direct control of the neutron yield, so that the experiment can utilize diagnostics that would not be useable with the higher neutron yield of a 50:50 D:T ratio. A recent example is the THD ConA, where the imploding target was backlit as in a ConA, just described, and the $\mathrm{D}$ was reduced to $2 \%$ in order to allow optimal signal from the x-ray diagnostics. Originally THDs were planned as surrogates for DT in fully optimized ignition implosions. At the time of this writing, the implosion has not yet been optimized enough for this to be relevant, and low-yield DT implosions have been used directly to explore the optimization as described in the following section. THD fuel composition is used in the occasional application, such as the ConA, where other diagnostic access is particularly relevant.

\section{DT IMPLOSIONS}


At the time of this writing there have been several dozen DT implosions, differing from an ignition implosion primarily in laser pulse shape. Specific requirements for the capsule and layer quality vary from shot-to-shot, depending on the purpose of the shot. For a "tuning" shot where integrated performance is not a priority, the DT layer is allowed to be somewhat rougher than for a high-performance experiment. Other than the layer quality and the details of the pulse shape, these targets generally meet ignition requirements. The pulse shape, including the wavelength difference and the cone-to-cone ratio, affect the key implosion parameters of symmetry, adiabat, and implosion velocity. Early shots, with lower laser power and energy, were dedicated to "tuning" some aspect of the implosion such as the wavelength difference between the cones; as NIC progressed, the laser power and energy have increased to the original ignition requirements.

The experiments have generally met the ignition target fabrication requirements. Two areas where we often fail to meet the requirements are (i) the mode 1 amplitude of the ice thickness; and (ii) the GDP outer surface, in modes around 10-20, which is sometimes rougher than the requirement by as much as $2 \mathrm{x}$ (in power). The sensitivity of performance to ice mode 1 is shown in Fig 5. The sensitivity to GDP surface has not been calculated recently and is not presented here. Two other areas are discussed in the following sections where it has become clear that more detailed attention is appropriate. The 3D perturbations from sphericity grow to be substantial shape deviations of the imploded configuration, as highlighted in Fig. 6.

The most important parameters measuring performance of the DT implosions are the neutron yield $Y$, and the fraction of the neutrons that are downscattered in energy as 
they leave the hotspot and traverse the compressed main fuel. The latter is termed Down Scattered Ratio (DSR), and is formally defined as the ratio of the $10-12 \mathrm{MeV}$ neutrons to the primary $13-15 \mathrm{MeV}$ neutrons. It is proportional to the column density of the main fuel. A combination of these two parameters, $\mathrm{Y} \times \mathrm{DSR}^{2.3}$, is known as ITFX and is predicted by simulations to be a good figure of merit measuring how close an implosion is to ignition. ${ }^{11}$ ITFX is normalized so that a value of unity should correspond to an implosion that barely ignites. (ITFX was originally intended as a figure of merit for THD implosions, for which achieving ITFX around unity is sensible; for DT we expect that as ITFX approaches unity the yield should increase rapidly so that ITFX $=1$ per se is not a sensible expectation.) Progress in this space is shown in Fig. 7. Early shots, before shocks and symmetry were tuned, had very low compression as measured by DSR. Improving the shocks and symmetry, tuning the hohlraum radius, switching to Si-doped GDP, and further tuning of the shocks and symmetry have progressively improved DSR. The highest yield was obtained in late 2011 with relatively short high power pulses. The highest ITFX to date is about 0.1 , achieved in the moderate yield, high compression shots in spring 2012.

It is expected that some fraction of the gap between current shots at ITFX $=0.1$ and the goal of ITFX=1 can be closed with more laser power and energy, along with further optimization of the pulse shape and capsule thickness. Part of the gap is also due to unexpected physics that must be dealt with in the future. There appear to be three issues that need to be addressed:

(i) The low velocity, which is probably simply lower-than-expected coupling in the hohlraum. This can be accommodated with more laser power and 
energy - NIF has ample margin to deal with a $15 \%$ energy loss relative to simulations, if that were the only issue.

(ii) There is accumulating evidence for somewhat more mix than expected. This could be because the 3D deviations from sphericity, from target fabrication and radiation asymmetry, are bigger than our current model implements; or because low-mode variability creates thin regions in the main fuel through which mix can penetrate more readily; or because the growth of the perturbations is more than currently modeled, as could result from errors in equation of state or opacity; or because the physics of the mix is qualitatively different from the assumed structure of seed $\times$ growth, with important kinetic effects or turbulence.

(iii) In addition to the mix, there is a tendency for the target implosion parameters to indicate lower-than-expected hot-spot density. This was especially true for the early shots in 2011; more recent shots in 2012, which are better tuned, show better compression although more mix. Inadequate compression could result from 3D hydrodynamics within the usual paradigm of seed $\times$ growth, in which mix and/or low mode 3D hydro degrades the compression of the core, or it could result from some 1D pathology that changes the hot-spot adiabat, as could happen for example with anomalous $1^{\text {st }}$-shock compression.

Plans to address these issues are being developed at the time of this writing.

\section{CAPSULE SUPPORT TENT}


The capsule is supported between two films of Formvar, as shown in Fig. 2. The thickness of this tent has been an issue in the 2009-2012 experiments. The tent thickness was originally specified as $80 \mathrm{~nm}$ (Rev1), with the ignition spec increasing to $110 \mathrm{~nm}$ (Rev3-5). Early experiments in NIC were done with $300 \mathrm{~nm}$ tents, and more recent shots have reduced the tent thickness back to $100-150 \mathrm{~nm}$.

The tent seeds hydrodynamic instabilities as follows. Within about $45^{\circ}$ of each pole, the tent confirms to the spherical capsule, so that the capsule is effectively thicker by the thickness of the tent film; close to the equator, the tent is far from the capsule surface and has at most a gradual low-mode effect on the implosion symmetry; just below the contact ring at about $45^{\circ}$, as the tent moves away from the capsule, it seeds a perturbation with amplitude approximately equal to the film thickness, and a lateral scale that is nontrivial to estimate. Without detailed modeling, one can only estimate that there is a perturbation seeded around the contact ring, which is of amplitude comparable to the film thickness.

Bang-time perturbations that have the right symmetry for this effect, and with amplitude close to our best estimate, are often evident in the x-ray emission images of the implosion experiments. An example is shown in Fig. 8. (This shot, N110904, was Sidoped, 1x, 195 thickness, in a 575 hohlraum, with an early pulse-shape optimization that was later improved. The purpose of this particular shot was to improve the azimuthal asymmetry with 3-wavlength tuning.) They are more often seen in symcaps, perhaps because other more random perturbation seeds are also important in the higherconvergence DT implosions. 
Direct numerical simulation of the tent is very difficult since the topology requires zoning perturbations that can dominate the actual physical effect. The best approach that has been taken to date is to run a series of $1 \mathrm{D}$ simulations with the tent at various altitudes above the capsule surface, and assume that the early-time hydrodynamics under each tent elevation is close to what the 1D simulation indicates. This set of simulations suggests a lateral scale of about $100 \mu \mathrm{m}$ to the perturbation, seeded just below the contact ring. Then a 2D simulation can be set up that has the same early-time perturbation, set up as a smoothly varying effective capsule thickness. A simulated image of this type is shown in the inset in Fig. 8, where it is evident that the simulated perturbation has an amplitude qualitatively similar to that observed. It is also evident that the contact ring, at $30^{\circ}$ in this simulation, is placed too close to the pole; after this simulation was run, the simulation team learned that the true location of the contact ring is closer to $45^{\circ}$. The size of the simulated image is also notably smaller than the observed image, in keeping with the tendency described above for the simulated hot-spot density to be too high. This tendency is still not understood, although it has become less evident in recent, better tuned, shots.

Given these results, it is very likely that the $300 \mathrm{~nm}$ tent that NIC used in early shot was too thick. Shots currently use $110-150 \mathrm{~nm}$ tent films, and work is being done to make thinner films.

\section{OXYGEN IN ABLATOR}

One issue that is not adequately covered in the Rev5 is the impact of an oxygen profile in the GDP. Capsule characterization indicates that there is up to 4 at $\%$ oxygen 
near the surfaces of the GDP, dropping to the baseline of $\sim 0.5$ at $\%$ with about a $50 \mu \mathrm{m}$ radial length scale. ${ }^{19}$

Uniform oxygen contamination has been addressed fully; the requirement is that the oxygen be less than 1 at $\%$; each at $\%$ of oxygen reduces the implosion velocity by $1.9 \%$, which is acceptable but requires more laser energy and concomitant risk of LPI and mix.

On the other hand, the Rev5 requirements do not directly address the $4 \%, 50 \mu \mathrm{m}$ oxygen profile. (There is a requirement that there be less than "the equivalent of a 100nm layer of 50\% oxygen," which would allow a 4\% layer to be only $1.25 \mu \mathrm{m}$ thick.) Simulations were done with the profile shown in Fig. 9, which is merely an approximate match to characterization data. ${ }^{19}$ This layer of oxygenated GDP reduces ablation pressure during the early part of the pulse, when the first shock is being launched. It delays the shock by about $100 \mathrm{ps}$, which is twice the requirement for how accurately this shock needs to be timed. The first shock causes a rarefaction that affects the timing of the $2^{\text {nd }}$ and $3^{\text {rd }}$ shocks, so they are also changed in their timing by $50-100 \mathrm{ps}$. The net effect is to increase the adiabat of an optimally timed target from 1.44 to 1.47 , a loss of $8.5 \%$ in the energy-equivalent margin parameter defined in Refs 5 and 8. Overall, then, this oxygen profile is certainly an issue that needs to be characterized and monitored, but is not a critical factor that hugely impacts target performance.

A related issue that has not been addressed is whether this oxygen in the GDP is laterally uniform. This should be addressed in the future, both to obtain better characterization of its uniformity, and analysis of how uniform it needs to be. 


\section{FUTURE DIRECTIONS}

The original NIC plan was to optimize experimentally the parameters associated with the Rev5 point design. One attractive aspect of this strategy was that it allowed for focused target fabrication. However, this strategy has now evolved into experimental optimization, exploring a variety of similar designs. For the near term NIC campaign, we are testing various configurations within the variations allowed by Fig. 1:

(i) Different dopant profiles, the " $1 \mathrm{x}$ " configuration with layers of 0-1-2-1-0 at $\% \mathrm{Si}$, and the " $2 \mathrm{x}$ " configuration with layers of $0-2-4-2-0$ at $\% \mathrm{Si}$;

(ii) Different thicknesses, ranging from 195 to $235 \mu \mathrm{m}$ GDP thickness;

(iii) Uniformly doped GDP, with Si dopant 0.5-2 at\%;

(iv) In some targets, called "co-doped", some of the $\mathrm{Si}$ is replaced in some layers by small amounts of Ge, to allow spectroscopic characterization of the mix.

Along with these capsule variations, we are exploring Au and U hohlraums. U clearly gives higher drive, but there are suggestions that $U$ targets may perform less well. It is not clear yet whether the performance changes are purely a result of the increased drive, or of some other aspect of the U-hohlraum experiments.

In addition to this experimental optimization of the target, we are putting together focused experiments to measure key aspects of the target physics:

(i) $2 \mathrm{D}$ ConA, in which the imploding shell is captured in a framed x-ray backlit image at about $300 \mu \mathrm{m}$ radius;

(ii) 3-axis keyhole, where the VISAR measures shock trajectories along 3 axes rather than the single or dual that have been done to date; 
(iii) Refraction Enhanced Imaging, a ConA-like backlit-capsule configuration but with the geometry arranged to enhance refractive effects that might allow measurement of the in-flight density profile;

(iv) Compton radiography of the imploded high-density fuel; and

(v) Rayleigh-Taylor experiments in which a deliberately perturbed capsule is backlit and the perturbation growth measured directly.

This variety of experimental platforms will allow much more detailed understanding of the implosion and its features.

Finally, alternate ablators designs as described in Ref. 5 are still under active consideration - ablators of high density carbon, possibly doped with $\mathrm{Si}$, and of Be doped with $\mathrm{Cu}$.

\section{CONCLUSION}

The National Ignition Campaign is well underway, with many successes in hand and some challenges ahead. We have successfully fielded all of the experimental platforms planned for NIC, and used the results to adjust the target design and laser pulse. Optimization of the original point design, and exploration of minor variants around it, have led to increasing understanding of the challenges facing ignition. Future experiments will be investigating this target physics in detail, determining the best possible ignition experiment and developing good understanding of its performance.

The target fabrication community deserves to be hugely congratulated for successfully fielding a wide variety of complex experiments, meeting diverse challenging 
requirements and a demanding schedule. The track record that they have established bodes well for the future, as we move into an even wider variety of experiments leading to detailed understanding of ignition science.

\section{ACKNOWLEDGEMENT}

This work was performed under the auspices of the U.S. Department of Energy by Lawrence Livermore National Laboratory under Contract DE-AC52-07NA27344.

\section{REFERENCES}

1. G. H. MILLER, E. I. MOSES, and C. R. WUEST, “The National Ignition Facility,” Opt. Eng. 443, 2841 (2004).

2. J. D. LINDL, P. A. AMENDT, R. L. BERGER, S. G. GLENDINNING, S. H. GLENZER, S. W. HAAN, R. L. KAUFFMAN, O. L. LANDEN, and L. J. SUTER, "The Physics Basis for Ignition Using Indirect-Drive Targets on the National Ignition Facility,” Phys. Plasmas 11, 339 (2004).

3. S. W. HAAN, M. C. HERRMANN, P. A. AMENDT, D. A. CALLAHAN, T. R. DITTRICH, M. J. EDWARDS, O. S. JONES, M. M. MARINAK, D. H. MUNRO, S. M. POLLAINE, J. D. SALMONSON, B. K. SPEARS, and L. J. SUTER, "Update on Specifications for NIF Ignition Targets, and Their Rollup into an Error Budget,” Fusion Sci. Technol. 49, 553 (2006).

4. S. W. HAAN, P. A. AMENDT, D. A. CALLAHAN, T. R. DITTRICH, M. J. EDWARDS, B. A. HAMMEL, D. D. HO, O. S. JONES, J. D. LINDL, M. M. MARINAK, D. H. MUNRO, S. M. POLLAINE, J. D. SALMONSON, B. K. SPEARS, and L. J. SUTER, "Update on Specifications for NIF Ignition Targets," Fusion Sci. Technol. 51, 509 (2007).

5. S. W. HAAN et al., "NIF Ignition Target Requirements, Margins, and Uncertainties: Status February 2010," Fusion Sci. Technol. 59, 1 (2011). 
6. G. B. ZIMMERMAN and W. L. KRUER, "Numerical Simulation of Laser-Initiated Fusion," Comments Plasma Phys. Controlled Fusion 2, 51 (1975).

7. M. M. MARINAK, R. E. TIPTON, O. L. LANDEN, T. J. MURPHY, P. A. AMENDT, S. W. HAAN, S. P. HATCHETT, C. J. KEANE, R. McEACHERN, AND R. WALLACE, “ThreeDimensional Simulations of Nova High Growth Factor Capsule Implosions,” Phys. Plasmas 3, 2070 (1996).

8. S. W. HAAN et al., "Point Design Targets, Specifications, and Requirements for the 2010 Ignition Campaign on the National Ignition Facility," Phys. Plasmas 18, 051001 (2011).

9. O. L. LANDEN et al., "Capsule Implosion Optimization During the Indirect-Drive National Ignition Campaign,” Phys. Plasmas 18, 051002 (2011).

10. M. J. EDWARDS et al., "The Experimental Plan for Cryogenic Layered Target Implosions on the National Ignition Facility—the Inertial Confinement Approach to Fusion,” Phys. Plasmas 18, 051003 (2011).

11. B. K. SPEARS et al., "Performance Metrics for Inertial Confinement Fusion Implosions: Aspects of the Technical Framework for Measuring Progress in the National Ignition Campaign,” Phys. Plasmas 19, 056316 (2012).

12. A. J. MARTEN et al., Fusion Science and Technology 59, 14 (2011).

13. D. A. CALLAHAN et al., "The Velocity Campaign for Ignition on NIF," Phys. Plasmas 19, 056305 (2012).

14. H. F. ROBEY et al., "Shock timing experiments on the National Ignition Facility: Initial results and comparison with simulation," Phys. Plasmas 19, 042706 (2012).

15. S. H. GLENZER et al., "Cryogenic Thermonuclear Fuel Implosions on the National Ignition Facility," Phys. Plasmas 19, 056318 (2012).

16. L. M. BARKER and R. E. HOLLENBACH, "Laser Interferometer for Measuring High Velocities of Any Reflecting Surface,” J. Appl. Phys. 43, 4669 (1972); P.M. CELLIERS et al., “Accurate Measurement of Laser-Driven Shock Trajectories with Velocity Interferometry," Appl. Phys. Lett. 73, 1320 (1998). 
17. D. H. MUNRO et al., "Shock Timing Technique for the National Ignition Facility," Phys. Plasmas 8, 2245 (2001).

18. D. G. HICKS et al., "Convergent Ablator Performance Measurements," Phys. Plasmas 17, 102703 (2010).

19. M. STADERMANN, private communication (2011), and this proceedings. 


\section{FIGURE CAPTIONS}

Fig. 1. Central spherical fuel-ablator assembly of an ignition target.

Fig. 2. Ignition target, showing hohlraum enclosing central spherical capsule, 48 "quads" of laser beams entering at indicated angles, and Si paddles supporting hohraum.

Fig. 3. (i) Typical ignition laser pulse, which uses $400 \mathrm{TW}$ peak power, 1.6 MJ laser energy, to heat hohlraum to $300 \mathrm{eV}$. (ii) Corresponding hohlraum temperature as a function of time (right-hand-scale).

Fig. 4. Experimental geometry for a Keyhole target.

Fig. 5. Yield of a THD implosion, or low-yield DT, vs. amplitude of mode 1 in ice thickness. Shots are shown with no intended meaning to the y-axis value for the shots. Only selected shots are indicated by name. Some shots have been below the ignition requirement, but typically the layers have had P1 larger than the requirement, with indicated predicted effect on yield.

Fig. 6. Two-dimensional simulation of a DT implosion at time of peak burn, illustrating expected features of the implosion. Upper half are density isocontours, with grayscale indicated, and lower half shows materials. Features: (i) GDP surface roughness grows to very large perturbations of the DT/GDP interface; (ii) GDP penetrates about half-way through the high density compressed main fuel; (iii) larger perturbations are caused by 
support tent and ice grooves; (iv) material that was originally DT gas is highly convolved throughout hot-spot.

Fig. 7. Performance of DT and THD implosions. Most of the shots are DT; for THDs the yield plotted on the vertical axis is adjusted for isotopic composition. Contours are ITFX, proportional to $\mathrm{Y} \times \mathrm{DSR}^{2.3}$. Diamonds—early 2011, pre-tuning; squares—June 2011, after first tune; filled circles—Sept-Dec 2011, Si capsules, 575 hohlraums; open circles— early 2012 , Si, 575 , low power pulses, better symmetry and shock timing.

Fig. 8. X-ray emission image, waist view, of DT shot N110904. A systematic pattern of perturbations is evident that has the symmetry features one would expect from a perturbation caused by the tent. The inset shows a simulation of the $300 \mathrm{~nm}$ tent, which assumed the contact ring was at $30^{\circ}$. The contact ring is typically closer to $45^{\circ}$, which would agree better with the experiment. The simulation is on the same scale, showing that shots in this period did not compress nearly as much as simulations. Both the experimental and the simulated image are at time of peak brightness.

Fig. 9. Oxygen profile in GDP assumed for simulation purposes. The oxygen ramps up to 4 at $\%$ with a $40 \mu \mathrm{m}$ radial length scale, an exponential shape added to the 0.5 at $\%$ background. 


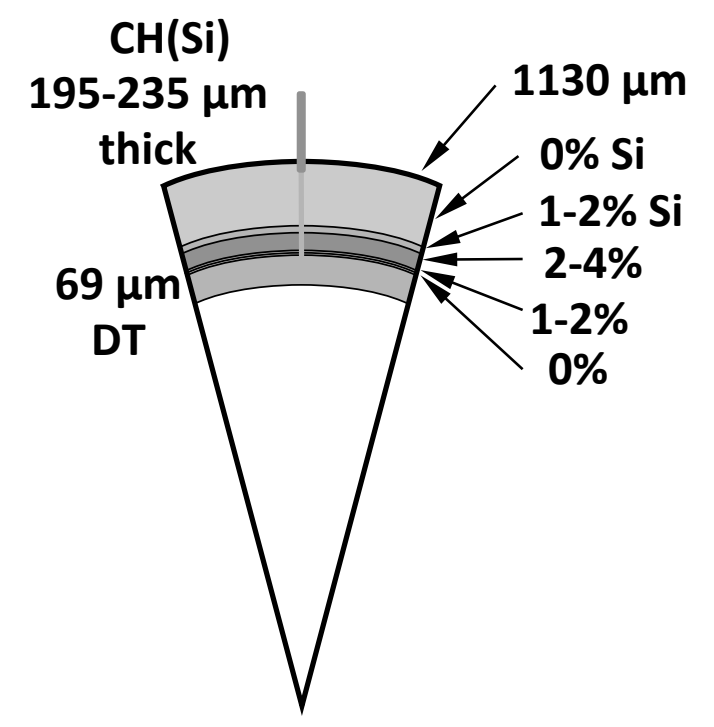

Fig. 1. Central spherical fuel-ablator assembly of an ignition target. 


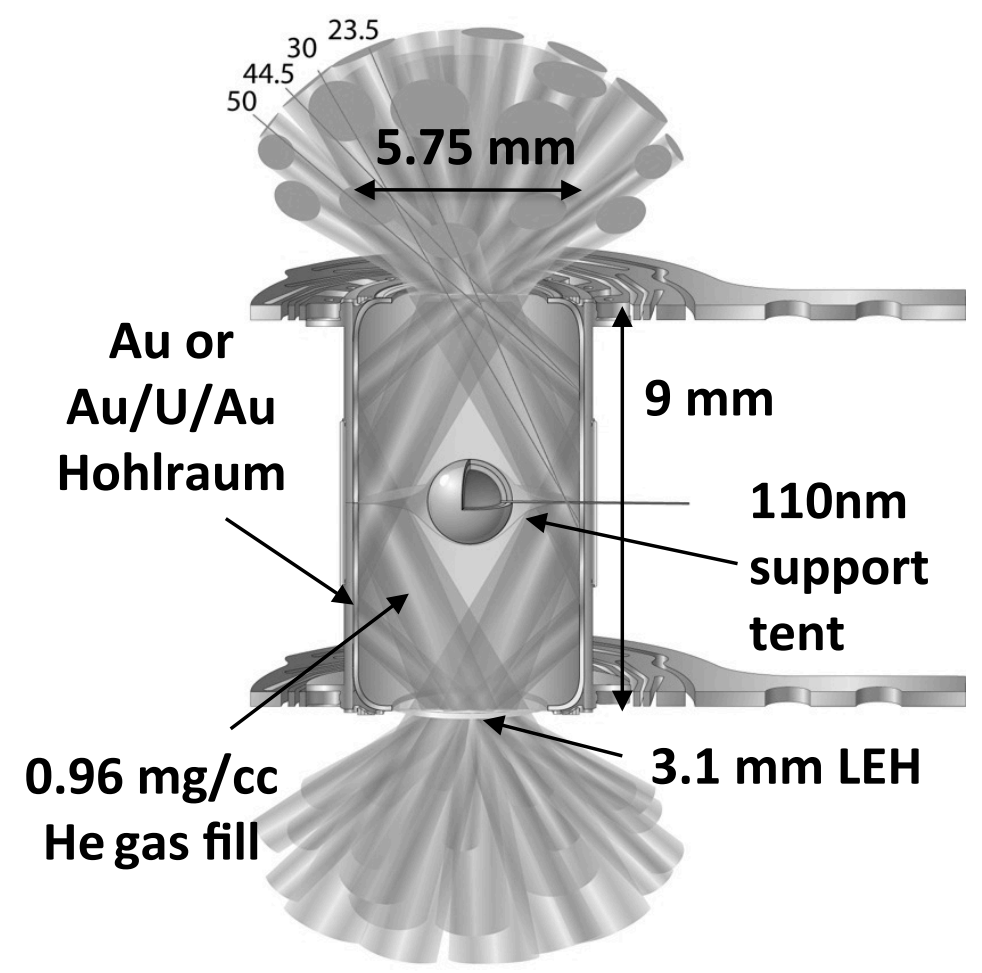

Fig. 2. Ignition target, showing hohlraum enclosing central spherical capsule, 48 "quads" of laser beams entering at indicated angles, and Si paddles supporting hohraum. 


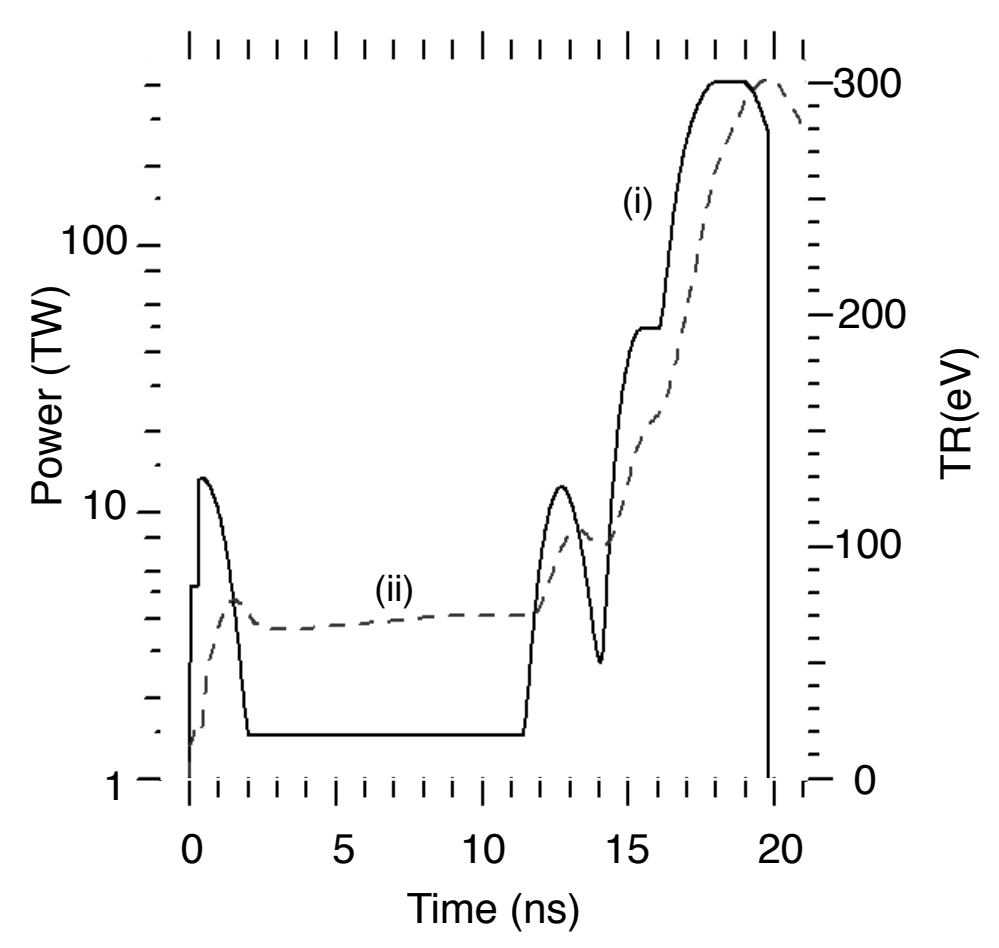

Fig. 3. (i) Typical ignition laser pulse, which uses $400 \mathrm{TW}$ peak power, 1.6 MJ laser energy, to heat hohlraum to $300 \mathrm{eV}$. (ii) Corresponding hohlraum temperature as a function of time (right-hand-scale). 


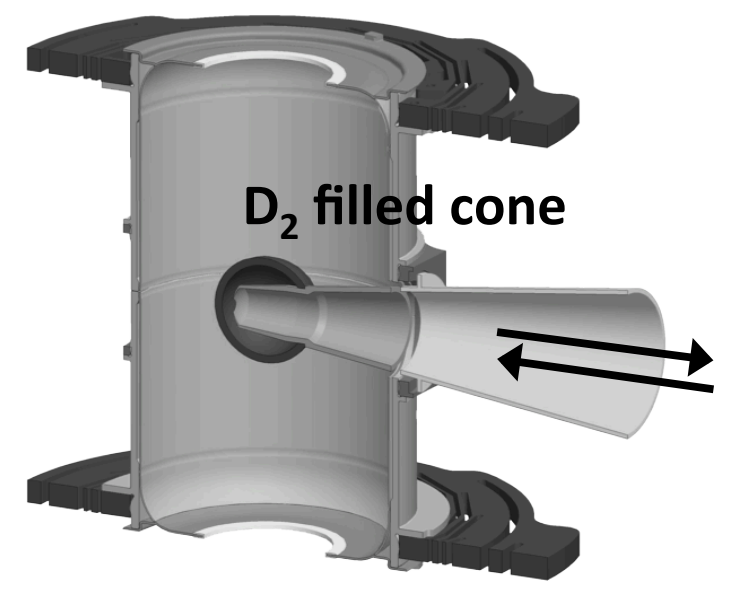

Fig. 4. Experimental geometry for a Keyhole target. 


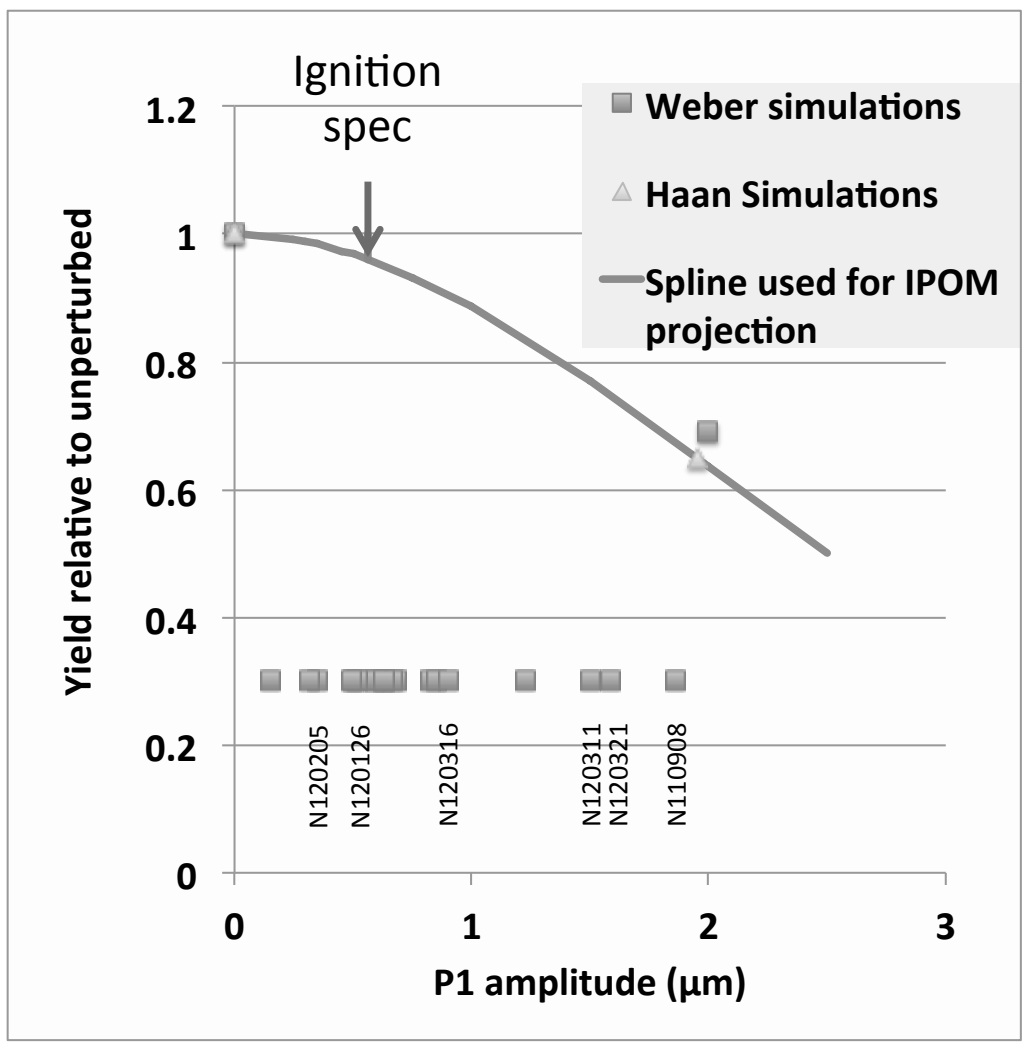

Fig. 5. Yield of a THD implosion, or low-yield DT, vs. amplitude of mode 1 in ice thickness. Shots are shown with no intended meaning to the y-axis value for the shots. Only selected shots are indicated by name. Some shots have been below the ignition requirement, but typically the layers have had P1 larger than the requirement, with indicated predicted effect on yield. 


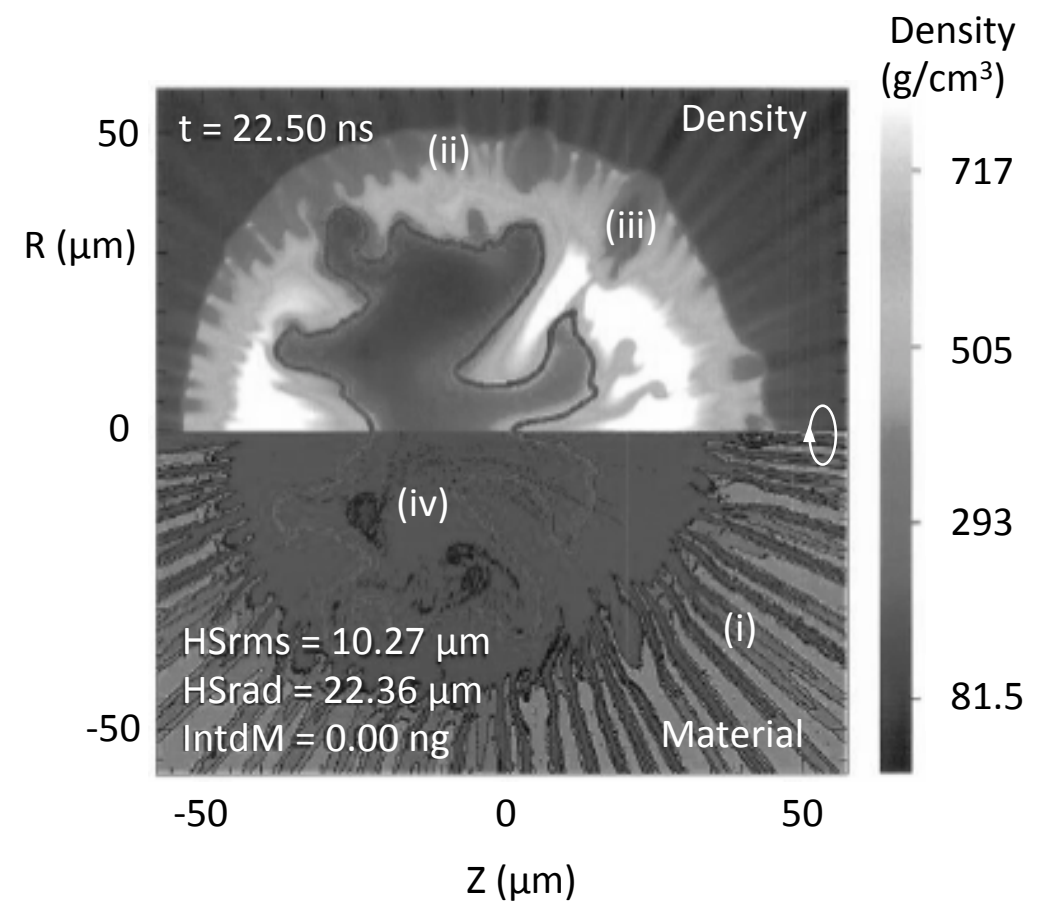

Fig. 6. Two-dimensional simulation of a DT implosion at time of peak burn, illustrating expected features of the implosion. Upper half are density isocontours, with grayscale indicated, and lower half shows materials. Features: (i) GDP surface roughness grows to very large perturbations of the DT/GDP interface; (ii) GDP penetrates about half-way through the high density compressed main fuel; (iii) larger perturbations are caused by support tent and ice grooves; (iv) material that was originally DT gas is highly convolved throughout hot-spot. 


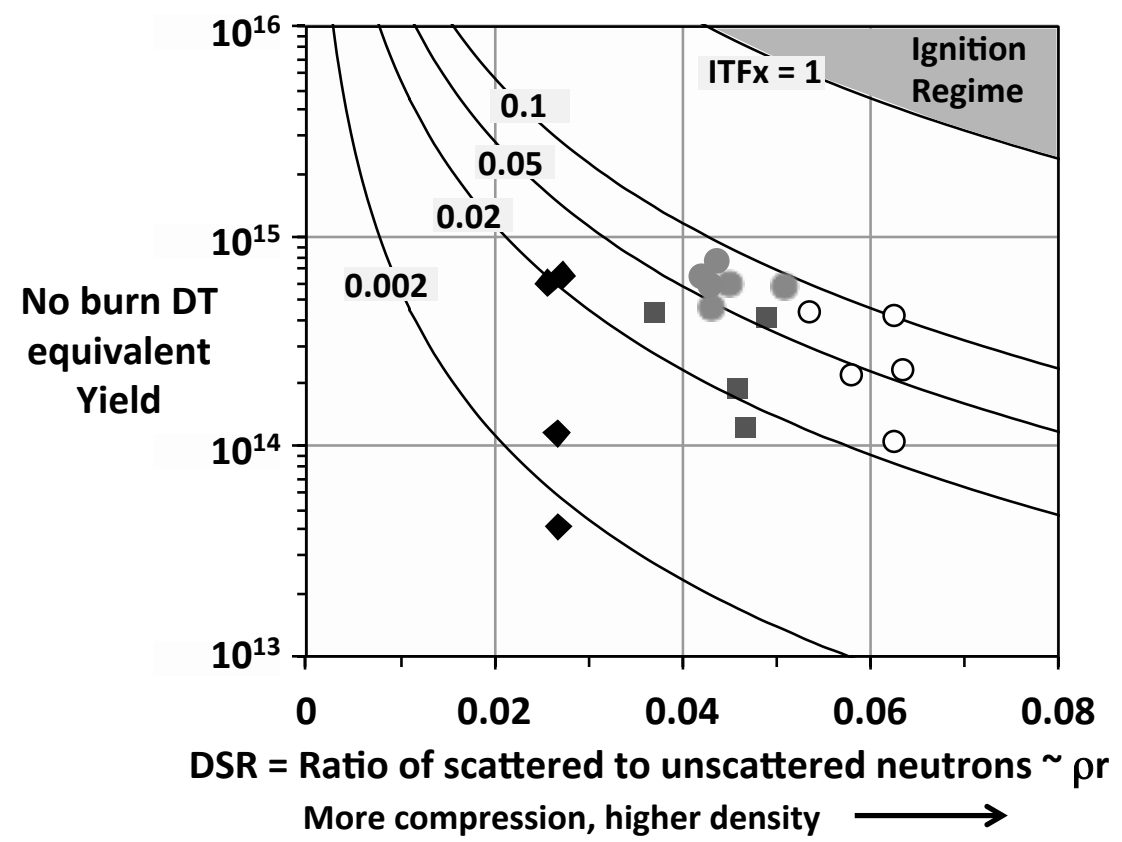

Fig. 7. Performance of DT and THD implosions. Most of the shots are DT; for THDs the yield plotted on the vertical axis is adjusted for isotopic composition. Contours are ITFX, proportional to $\mathrm{Y} \times \mathrm{DSR}^{2.3}$. Diamonds-early 2011, pre-tuning; squares - June 2011, after first tune; filled circles-Sept-Dec 2011, Si capsules, 575 hohlraums; open circles-early 2012, Si, 575, low power pulses, better symmetry and shock timing. 


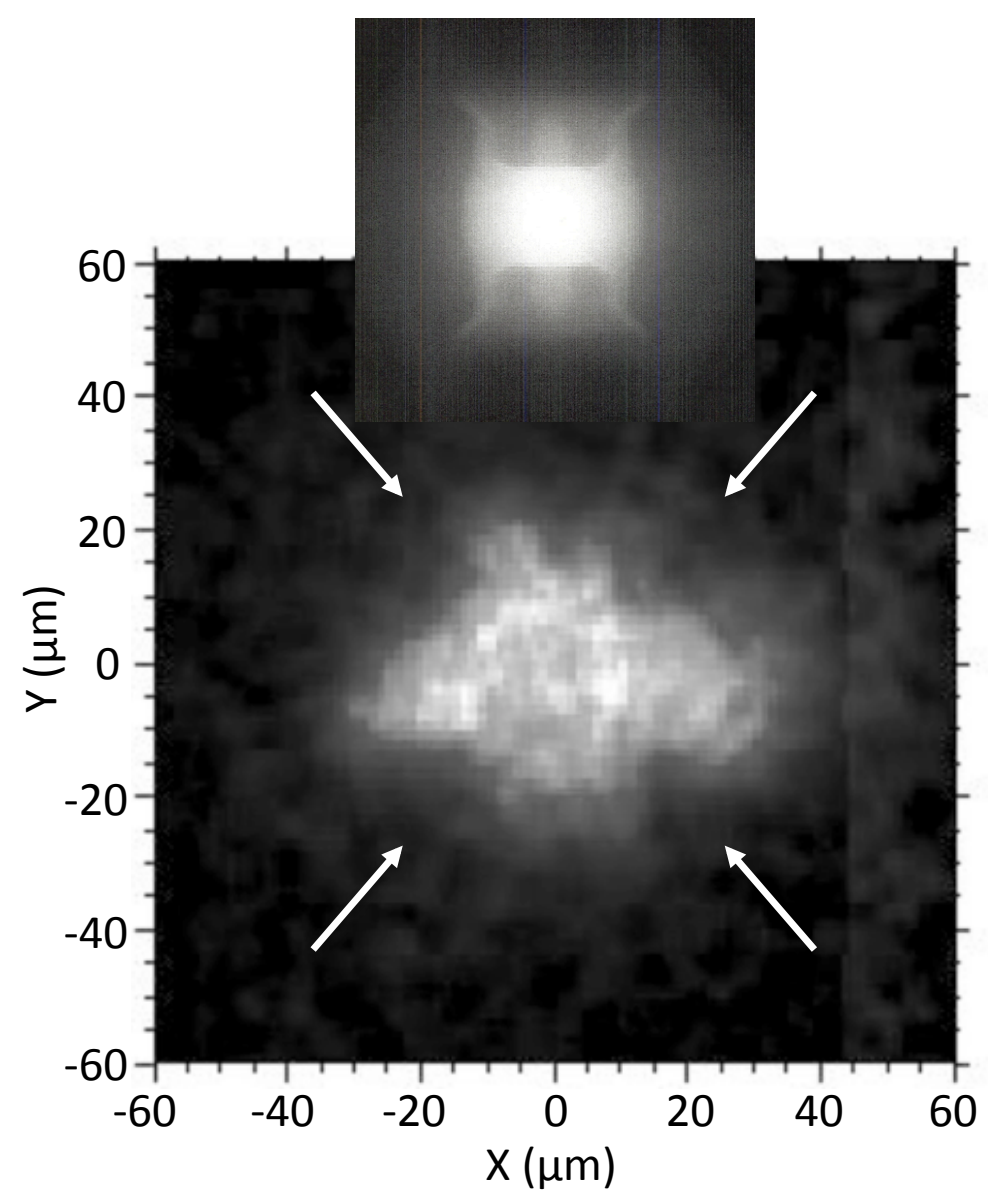

Fig. 8. X-ray emission image, waist view, of DT shot N110904. A systematic pattern of perturbations is evident that has the symmetry features one would expect from a perturbation caused by the tent. The inset shows a simulation of the $300 \mathrm{~nm}$ tent, which assumed the contact ring was at $30^{\circ}$. The contact ring is typically closer to $45^{\circ}$, which would agree better with the experiment. The simulation is on the same scale, showing that shots in this period did not compress nearly as much as simulations. Both the experimental and the simulated image are at time of peak brightness. 


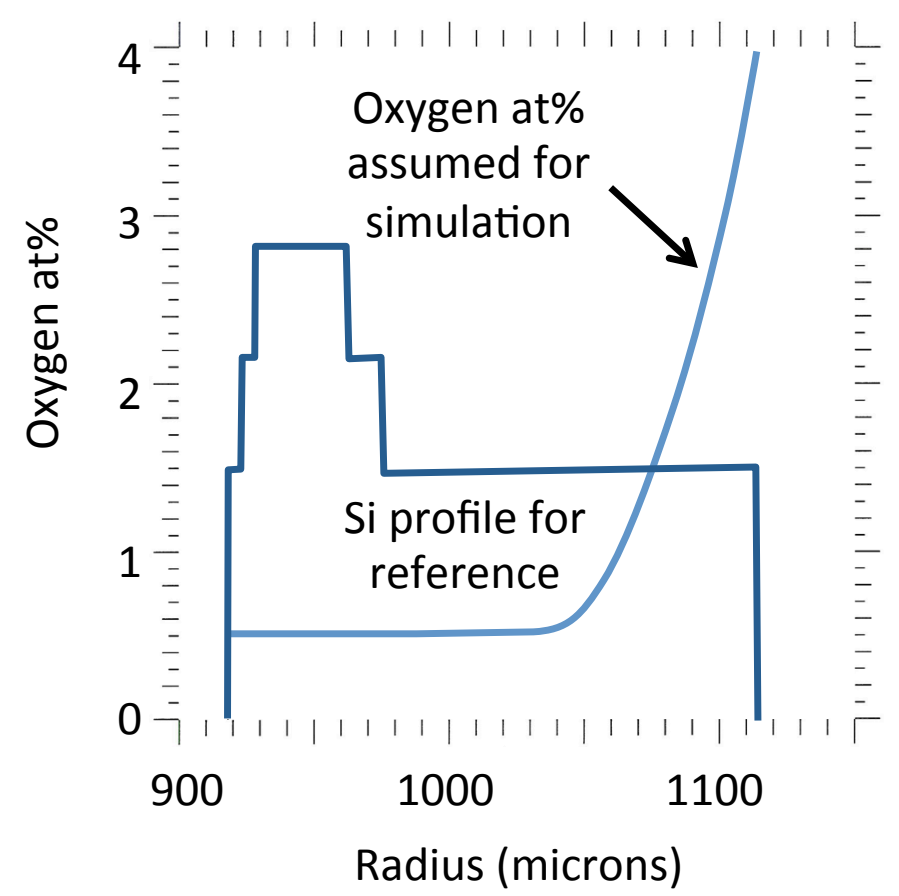

Fig. 9. Oxygen profile in GDP assumed for simulation purposes. The oxygen ramps up to 4 at $\%$ with a 40 $\mu \mathrm{m}$ radial length scale, an exponential shape added to the 0.5 at $\%$ background. 